\title{
FATE OF THE NEOPULMONARY VALVE AFTER THE ARTERIAL SWITCH OPERATION IN NEONATES
}

\author{
Shunji Nogi, MD \\ Brian W. McCrindle, MD, FACC ${ }^{\mathrm{a}}$ \\ Christine Boutin, MD \\ William G. Williams, MD, FACC ${ }^{\mathrm{b}}$ \\ Robert M. Freedom, MD, FACC ${ }^{\text {a }}$ \\ Lee N. Benson, MD, FACC ${ }^{\text {a }}$
}

\begin{abstract}
Objectives: The purpose of this study was to determine the incidence, risk factors, and outcomes of acquired stenosis of the neopulmonary valve after the neonatal arterial switch operation. Methods: Reviewed were the preoperative and follow-up echocardiograms from 136 of 288 patients undergoing the arterial switch operation for whom adequate studies were available. Pulmonary stenosis was defined as a thickened and doming pulmonary valve and a pressure gradient of $20 \mathrm{~mm} \mathrm{Hg}$ or more. Transposition of the great arteries was present with intact ventricular septum in 91 patients, with a ventricular septal detect in 39 , with an aortic coarctation in 5 , and with double-outlet right ventricle in 1 patient. No patient had preoperative valvular abnormalities (i.e., a bicuspid valve). Results: During a median follow-up of 18 months (range $<1$ to 90 months), 32 patients $(24 \%)$ had the development of supravalvular pulmonary stenosis, 15 (11\%) with associated pulmonary valve stenosis (group I). Kaplan-Meier estimates of freedom from any intervention were $94 \%$ (95\% confidence interval, $90 \%$ to 99\%) at 1 year and $79 \%$ (95\% confidence interval, 64\% to 94\%) at 5 years. The valve anulus before the arterial switch operation was significantly larger $(p<0.03)$ in those in whom neopulmonary valve stenosis did not develop (group II) than it was in those in whom it did (group I). At follow-up, the pulmonary valve anulus had decreased significantly in diameter in group I ( $p<\mathbf{0 . 0 0 0 5 )}$ and had remained larger in group II ( $p=$ 0.06) compared with normal diameter. Group I patients had the development of significant pulmonary valve hypoplasia $(p<0.03)$ whereas group II patients continued to have significantly larger valves compared with normal size $(p<0.0001)$. Conclusions: Neopulmonary valve stenosis after the arterial switch operation is not uncommon and is associated with growth failure of the valve anulus often associated with supravalvular pulmonary stenosis. (J Thorac Cardiovasc Surg 1998;115:557-62)
\end{abstract}

$T^{\mathrm{h}}$ he arterial switch operation (ASO) is the accepted, preferred treatment for transposition of the great arteries (TGA) in the neonatal period, with a low early and intermediate mortality rate. ${ }^{1-6}$

From the Department of Pediatrics and Surgery, ${ }^{\text {a }}$ Division of Cardiology and Cardiovascular Surgery, ${ }^{\text {b }}$ The Hospital for Sick Children, University of Toronto Faculty of Medicine, Toronto, Ontario, Canada.

Received for publication March 13, 1997; revisions requested May 8, 1997; revisions received Sept. 30, 1997; accepted for publication Sept. 30, 1997.

Address for reprints: Lee N. Benson, MD, Division of Cardiology, The Hospital for Sick Children, University of Toronto, Faculty of Medicine, 555 University Ave., Toronto, Ontario, Canada, M5G 1X8.

Copyright (c) 1998 by Mosby, Inc.

$0022-5223 / 98 \$ 5.00+0 \quad \mathbf{1 2 / 1 / 8 6 5 2 3}$
The most common complication in survivors is stenosis of the pulmonary arteries (supravalvular and branch pulmonary artery stenosis), with a reported incidence from $7 \%$ to $40 \% .^{6-8}$ Pulmonary artery stenosis may be related to the technique of reconstruction of the proximal pulmonary arteries with a patch to fill the defects in the posterior wall where the coronary artery buttons were excised ${ }^{9-11}$ or to distortion of the main and peripheral pulmonary arteries as a result of the anterior placement of the bifurcation (Lecompte's maneuver ${ }^{12}$ ). Neopulmonary valve (neo-PV) stenosis has been reported rarely in patients who have undergone either a one-stage ${ }^{8,13}$ or two-stage ASO. ${ }^{14}$ Staging with pulmonary artery banding has been noted a risk factor for development of neo-PV stenosis. ${ }^{14}$ However, the incidence, risk factors, and early outcome after a 
one-stage ASO in neonates have not been described. We sought to investigate these issues and reviewed preoperative and follow-up echocardiographic studies to discern correlations between neo-PV stenosis, morphologic features (i.e., size of the aortic valve [pre-ASO]), surgical technique, and coronary artery anatomy.

\section{Methods}

Study population. Between August 1986 and October 1995, 288 infants with TGA or double-outlet right ventricle underwent an ASO in the neonatal period at The Hospital for Sick Children, Toronto. Adequate follow-up data and echocardiograms before and after the ASO were available in 136 children.

Echocardiographic measurements. Echocardiograms were reviewed before repair and at a median interval of 18 months after repair (range $<1$ month to 90 months). Parasternal long- or short-axis views were used for evaluation of right and left ventricular outflow tracts. When the parasternal view was not adequate for measurement of right ventricular outflow tract dimensions, the subcostal right or left oblique view was used. ${ }^{15,16}$ Measurements were taken at the maximal diameter at each site. Pulmonary valve stenosis was considered present when pulmonary valve leaflets were seen to be thickened and doming and an echocardiographic peak instantaneous pressure gradient of more than $20 \mathrm{~mm} \mathrm{Hg}$ across the valve was documented. The diameters of the neo-PV anulus, neoaortic valve (neo-AV) anulus, main pulmonary artery (neo-mPA), and ascending aorta at anastomotic sites and the diameters of the left and right branch pulmonary arteries were measured. The ratio of the neo-PV anulus to the neo-AV anulus was calculated. For those patients with neo-PV stenosis, intervening serial studies were also reviewed. Supravalvular pulmonary stenosis was considered present when the region (diameter) above the pulmonary valve sinuses was less than that of the pulmonary valve anulus, with or without main pulmonary artery hypoplasia or the presence of branch pulmonary artery stenosis. A variety of echocardiographic machines were used with transducers of $3.5 \mathrm{MHz}$ or $5 \mathrm{MHz}$, and studies were recorded on an S-VHS videotape recorder.

Data analysis. Descriptive patient data and anatomic characteristics were recorded as frequencies, medians with ranges, and means with standard deviations as appropriate. Echocardiographic measurements were normalized as a z score related to body surface area (Dr. S. Colan, personal communication). These $\mathrm{z}$ scores were derived from nonlinear regression equations obtained from an age-appropriate normal population. The neo-PV anulus was normalized to be a normal PV anulus. The neo-AV anulus was normalized to be a normal AV anulus. Likewise, the neo-mPA was normalized to a normal mPA, and the neo-ascending aorta to a normal ascending aorta. Mean z scores were tested against the null hypothesis of a population mean of 0 with a Student's $t$ test. Changes in mean $\mathrm{z}$ scores within groups were tested with paired $t$ tests. Time to reintervention was plotted with the use of Kaplan-Meier estimates.

\section{Results}

Study population. The study population included 136 patients who had an ASO in the neonatal period $(<30$ days of life). TGA with intact ventricular septum was present in $91(66 \%)$ patients, TGA with a ventricular septal defect in $36(26 \%)$, TGA, ventricular septal defect, and coarctation in $4(3 \%)$, and double-outlet right ventricle (Taussig-Bing anomaly) in $1(1 \%)$. There were 97 boys and 39 girls. The ASO was performed at a median age of 6 days (range 0 to 28 days), body weight of $3.3 \mathrm{~kg}$ (range 1.7 to $4.7 \mathrm{~kg}$ ), and body surface area of $0.22 \mathrm{~m}^{2}$ (range 0.15 to $0.30 \mathrm{~m}^{3}$ ). Median follow-up interval was 18 months (range $<1$ month to 90 months).

Coronary artery anatomy. Coronary artery anatomy was determined from biplane aortic angiography or from operative findings and described with the classification of Yamaguchi. ${ }^{17}$ Patterns found were as follows: $1 \mathrm{LCx} 2 \mathrm{R}$ in $91(67 \%), 1 \mathrm{~L} 2 \mathrm{RCx}$ in 21 $(15 \%), 1 \mathrm{Cx} 2 \mathrm{RL}$ in $3(2 \%), 1 \mathrm{R} 2 \mathrm{LCx}$ in $4(3 \%)$, miscellaneous in $8(6 \%)(1 \mathrm{Cx} 2 \mathrm{R} 1 \mathrm{Acc}, 1 \mathrm{RCx} 2 \mathrm{Cx}$, 1L2R，1LR2Cx，1LCx[RArr]2R，1LCx[RAcc]2R, 1RLCx2R[Acc], $1 \mathrm{R}$ [Acc]2RLCx), and a single coronary artery in $9(7 \%)$ (1RLCx or 2RLCx: intramural coronary artery in 6).

Operation. The ASO was performed with cardiopulmonary bypass and circulatory arrest using Lecompte's maneuver with removal of coronary artery buttons and patch replacement of the valve sinus where the coronary buttons were excised. To close the defects in the sinuses, a single generous patch fashioned in a pantaloon-like shape was used in 123 patients (90\%), ${ }^{11}$ and 2 separate patches were used in 4 patients. Seven patients with a single coronary artery (intramural in 6) had a tunnel procedure (Takeuchi method ${ }^{18}$ ) performed. The defect in the neopulmonary artery was patched with fresh autologous pericardium in 84 patients $(63 \%)$ and glutaraldehyde-treated autologous pericardium in $52(38 \%)$. Ventricular septal defect closure or coarctation repairs were performed at the same operation as appropriate.

Supravalvular pulmonary stenosis and neo-PV stenosis. During follow-up, 32 (24\%) of the 136 patients had the development of supravalvular pulmonary stenosis (at the anastomotic site or the branch pulmonary arteries), with associated pulmonary valvular stenosis in 15 (11\%; group I). No patients had native aortic valve stenosis before the ASO ( 2 had mild thickening of the aortic valve without obstruction). Peak instantaneous pressure gradient by Doppler echocardiography through the 
neo-PV was $53 \pm 24 \mathrm{~mm} \mathrm{Hg}$ in those in whom stenosis developed. The neo-PV was tricuspid in all but one patient, in whom obstruction did not develop. Group II consisted of 121 patients with normal neo-PV flows including the 17 patients with supravalvular pulmonary stenosis. Subvalvular stenosis was seen in 14 patients (10\%; 4 in group I and 10 in group II).

Intervention. Ten of 11 patients having intervention had associated neo-PV stenosis. Intervention for right ventricular outflow tract obstruction was required in 11 patients and included subpulmonary myotomy and pulmonary valvotomy in 2 , subpulmonary myotomy and transannular patch in 4, right ventricle to pulmonary artery external conduit in 2 , and percutaneous balloon dilation in 3 (effective in $2)$. Ten of 11 patients having intervention had associated neo-PV stenosis. Kaplan-Meier estimates of freedom from intervention were 94\% (95\% confidence interval, $90 \%$ to $99 \%$ ) at 1 year and $79 \%$ (95\% confidence interval, $64 \%$ to $94 \%$ ) at 5 years (Fig. 1).

Risk factors for neo-PV stenosis. Neo-PV stenosis occurred in $10 \%$ of male and $13 \%$ of female patients $(p=0.77)$. The median (range) age at ASO was 6 days (0 to 28) for patients without neo-PV stenosis versus 5 days (2 to 19) for patients with neo-PV stenosis $(p=0.78)$. Neo-PV stenosis developed in $11(12 \%)$ of 91 patients with TGA and intact ventricular septum compared with 4 (9\%) of 44 patients with TGA and a ventricular septal defect $(p=0.78)$. Coronary artery pattern did not relate to the development of neo-PV stenosis, with stenosis in $10(11 \%)$ of 91 patients with normal anatomy (1L2RCx) compared with stenosis in $5(11 \%)$ of 45 patients with abnormal origins $(15 \%$ with a single coronary artery). The pulmonary artery patch material used was also not associated with the development of valve stenosis, which occurred in $10(12 \%)$ of 84 patients with a patch of untreated autologous pericardium versus $5(10 \%)$ of 52 patients in whom the pericardium was treated with glutaraldehyde $(p=0.71)$.

The aortic valve annular diameter before the ASO was significantly larger in group II $(0.79 \pm$ $0.98)$ compared with that in group I $(0.20 \pm 1.05)$ ( $p=0.03$; Fig. $2, A$; measurements given as $\mathrm{z}$ values). At follow-up, the neo-PV anulus had decreased significantly in size in both groups, but the degree of growth delay was greater $(p=0.04)$ in group I $(\Delta \mathrm{z}$ score $-1.56 \pm 1.24, p=0.0003$ from normal) than in group II $(\Delta \mathrm{z}$ score $-0.52 \pm 1.80$,

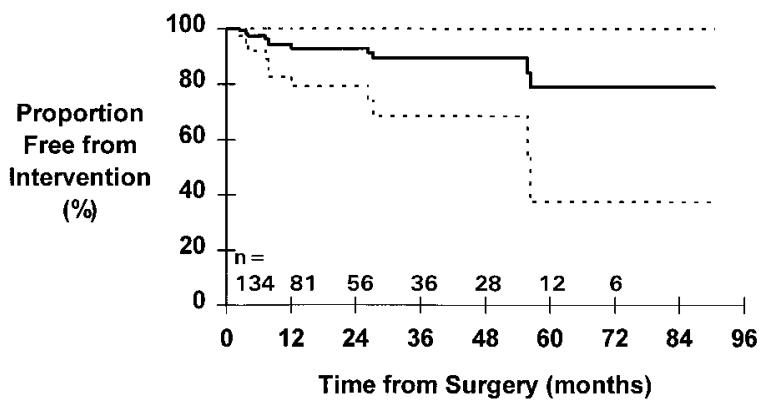

Fig. 1. Kaplan-Meier estimates of freedom from intervention for neo-PV stenosis and supravalvular pulmonary stenosis. Dotted lines represent $95 \%$ confidence limits.

$p=0.003$ from normal). Group I patients had the development of significant neo-PV annular hypoplasia $(-1.36 \pm 0.94, p=0.0001$ from normal $)$ after repair, whereas group II patients continued to have significantly larger valves $(p<0.0001)$ than normal $(0.31 \pm 1.44, p=0.03$ from normal).

There were also significant changes and differences in the dimensions of other structures between the two groups. Both groups had larger than normal PV anuli (pre-ASO) $(1.18 \pm 1.12, p=0.003$ in group I; $1.37 \pm 0.92, p<0.0001$ in group II) and continued to have large neo-AV anuli (post-ASO) that were significantly greater than normal $(2.15 \pm$ $1.94, p=0.0008$ in group I; $1.89 \pm 1.54, p<0.0001$ in group II) (Fig. 2, B). Both groups had normal dimensions of the ascending aorta before repair $(-0.05 \pm 1.40, p=0.89$ in group $\mathrm{I} ; 0.13 \pm 0.79, p=$ 0.07 in group II) and significantly smaller than normal dimensions after repair (neo-mPA) $(-1.97 \pm$ $1.61, p=0.0003$ in group $\mathrm{I} ;-1.07 \pm 1.70, p<0.0001$ in group II), which were greater in group I ( $p=$ 0.005) (Fig. 2, C). Group I had normal main pulmonary artery dimensions before the operation $(0.04 \pm$ $1.13, p=0.89$ ), and group II had larger than normal dimensions $(0.27 \pm 1.02, p=0.005)$, and in both groups these became smaller than normal after repair (the neoaortic root) $(-1.70 \pm 1.25, p<0.0001$ in group I; $-1.76 \pm 1.64, p<0.0001$ in group II), with no differences between groups (Fig. 2, D). Likewise, there were no significant differences between groups before or after repair regarding the ratios between semilunar valves or branch pulmonary arteries.

The median time of follow-up after ASO was slightly shorter for those with neo-PV stenosis $(0.7$ years, range $<1$ month to 5.8 years) than for those without ( 1.5 years, range $<1$ month to 7.5 years; $p=$ 


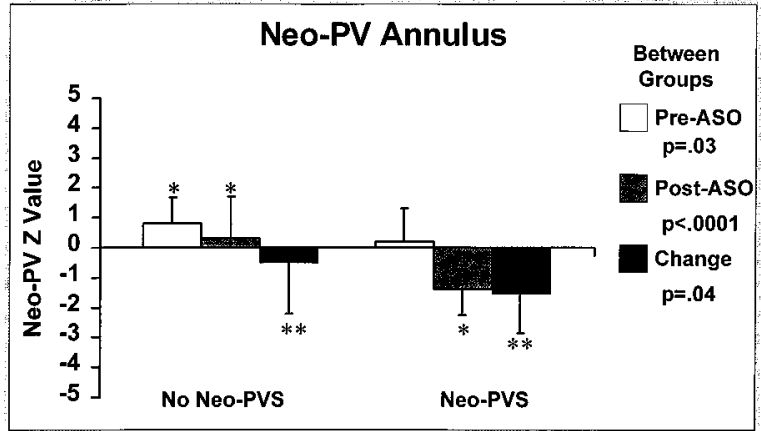

A

${ }^{*} p<.05$ from normal; ${ }^{* *} p<.05$ for change pre- to post-ASO

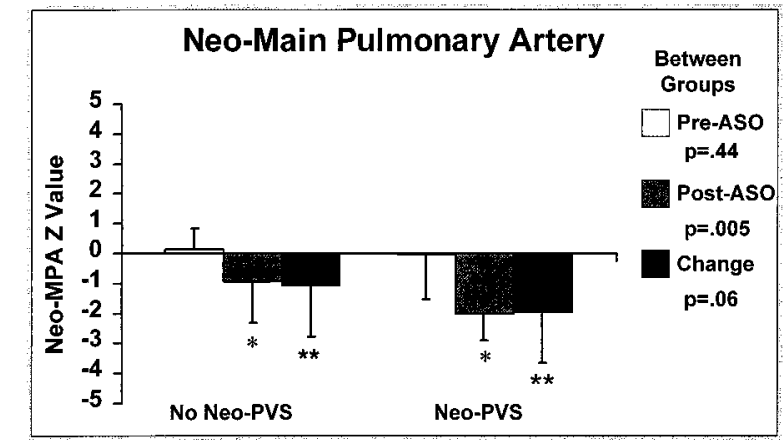
C

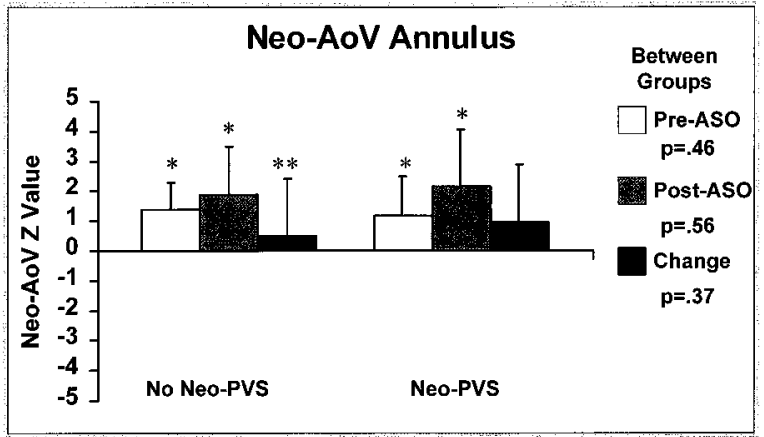

B

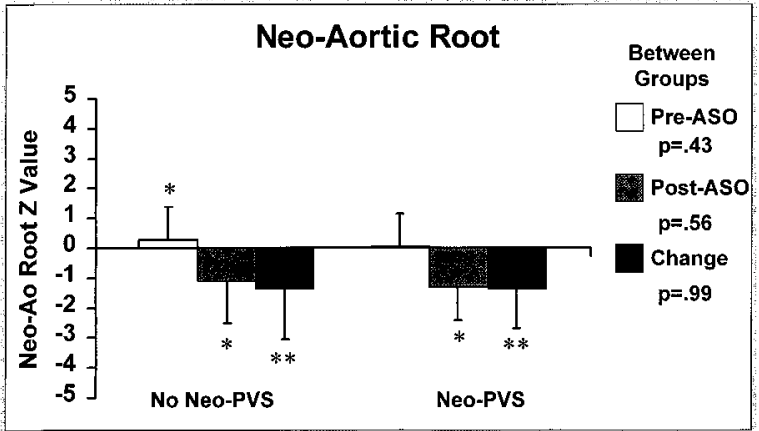

D

Fig. 2. Echocardiographic measurements. A, The relationship of neo-PV anulus before and after ASO. B, The relationship of neoaortic valve (neo- $\mathrm{AoV}$ ) anulus before and after ASO. C, The relationship of neopulmonary artery before and after ASO. D, The relationship of neo-ascending aorta between before and after ASO.

0.17). When changes in dimensions were divided by the time over which the change occurred, group I patients continued to have significantly greater growth failure of the neo-PV anulus than patients in group II.

Likewise, when dimensions were normalized to the structure they were, that is, neo-PV anulus normalized to a normal aortic anulus, there were no significant changes in the results of the analysis.

\section{Discussion}

Supravalvular pulmonary stenosis and neo-PV stenosis

Incidence. The most commonly appreciated complication after the ASO is supravalvular pulmonary artery stenosis with an incidence of $24 \%$ in this series. With attention to this issue through the use of improved surgical technique, the incidence has been decreasing. ${ }^{9}{ }^{19}$ Few reports, however, have addressed the issue of acquired neo-PV stenosis. Our series noted an incidence of neo-PV stenosis of $11 \%$, and small aortic anulus before the operation predicted the development of neo-PV valve stenosis after repair. Martin ${ }^{8}$ and Gleason ${ }^{13}$ and their colleagues identified neo-PV stenosis after a singlestage repair in $4 \%$ and $9 \%$ of patients, respectively. Whereas the single-stage ASO and reconstruction of the pulmonary artery with a pantaloon-shaped fresh autologous pericardial patch have decreased the incidence of supravalvular stenosis, ${ }^{9}$ right ventricular outflow tract obstruction (valvular and supravalvular) was still recognized with use of the single pantaloon patches. In our series, 15 (11\%) of 136 patients had the development of neo-PV stenosis, which could be related to surgical factors associated with supravalvular stenosis.

Preoperative risk factors. In this study, the pulmonary anulus in group I patients was significantly smaller than that in group II patients, and growth failure of the neo-mPA was noted in both groups. In 
previous studies the size mismatch between the great arteries and a smaller aortic anulus when a coarctation was present has been shown to be a risk factor for the development of postoperative pulmonary valve stenosis. ${ }^{20-22}$ However, the presence of a coarctation in this study appeared not to be related to the presence of the small neo-PV anulus. The basis for the larger AV anulus in both groups before the ASO is difficult to explain. It is our impression that flow through the native aortic valve in TGA, through the fetal and early neonatal periods, is significantly greater than that in a normal heart because of intracardiac shunting, but for some reason, right ventricular stroke output was smaller (and thus the aortic anulus smaller) in that subgroup of patients in whom stenosis developed. Wernovsky and associates ${ }^{23}$ reported that risk factors of supravalvular pulmonary stenosis and neo-PV stenosis were associated with the coronary artery pattern and a younger age at operation. However, no relationship between these factors and stenosis was seen in our review.

Surgical risk factors. Pulmonary artery stenosis after ASO occurs in two patterns, being either discrete or diffuse. ${ }^{24}$ Diffuse hypoplasia of the main pulmonary artery may result from inadequate mobilization of the branch pulmonary arteries, resulting in tension on the anastomosis. Circumferential narrowing at the suture line may also occur and result in a more discrete type of stenosis. In our series, 13 of 15 patients in group I had associated diffuse pulmonary artery hypoplasia. Spiegelenberg $^{25}$ and Wernovsky ${ }^{19}$ and their colleagues suggested that the supravalvular stenosis may also result in semilunar valve distortion and stenosis, implying that inadequate mobilization may ultimately result in the valve anulus disorder.

Additionally, both pulmonary artery banding ${ }^{20}$ and the type of patch procedure used to correct the defects in the pulmonary artery wall (from the coronary artery buttons) $)^{9-11}$ have been suggested as technical factors that can lead to valvular and supravalvular stenosis. Nakanishi and coworkers ${ }^{14}$ suggested that the neo-PV anulus may be abnormally small after the ASO and noted a small anulus or lack of annular growth being more frequent in patients who had pulmonary artery banding. Furthermore, anterior compression by the aorta may tent forward the pulmonary artery and distort the neo-PV anteriorly, altering geometry and interfering with growth. This study additionally noted that the neo-PV anulus at follow-up had decreased significantly in size in both groups, but more in group II.

In our series, the operation was performed with a standardized technique for repair of the buttons (a generous single pantaloon-shaped patch of fresh or glutaraldehyde-treated autologous pericardium). Therefore the technique for right ventricular outflow tract reconstruction appeared in our hands not to be related to the development of neo-PV stenosis, although the influence of varying the number of patches used could not be assessed, because only a single patch method was used. Furthermore, the type of materials used for the patch was not related to stenosis development. At reintervention in two group I patients, however, we did note that there was annular retraction in the posterior wall in the region of the button patches, and all but one patient had associated narrowing of the neo-mPA (hypoplastic main pulmonary artery). This observation suggests that tissue degeneration around neo-PV leaflets can occur after repair and that mechanical traction or distortion from inadequate mobilization leads to deterioration of the neo-PV cusps. The suggestions of Yasui $^{26}$ and Spiegelenberg ${ }^{25}$ and their colleagues that retraction of the patches resulted in narrowing of the main pulmonary artery, as well as distortion and stenosis of the pulmonary valves, are supported by these observations. Data in this study would also support the idea that mechanical torsion or tension on a small anulus can lead to impaired growth.

When does neo-PV stenosis occur? In $11(73 \%)$ of 15 patients, neo-PV stenosis developed within the first year after repair, whereas in $4(17 \%)$ of 15 the lesion developed beyond 1 year after the operation. This observation concurs with the suggestion of other investigators that neo-PV stenosis tends to develop primarily during the first year after repair. ${ }^{23}$ In our series neo-PV stenosis has been responsible for $60 \%$ of the reoperations or percutaneous catheter interventions.

Growth of neo-AV anulus and ascending aorta. The neo-AV anulus before the ASO was significantly larger in both groups as noted by Hourihan and associates. ${ }^{27}$ The cause for dilation of the pulmonary valve anulus before repair in both groups may relate to a larger volume of flow across the native pulmonary valve. Interestingly, the neo-AV anulus in both groups tended to remain larger after the operation, ${ }^{27}$ and it showed normal growth. The ascending aorta (native pulmonary artery) before the ASO was also significantly larger than that in the normal 
population in both groups. This may be a result of the high flow pulmonary circulation in TGA after birth. On the other hand, the diameter of the ascending aorta normalized after repair in both groups and was not significantly different between groups. The low growth rate of the anastomotic sites after the end-to-end anastomosis may influenced the normalization of dimensions after the operation. ${ }^{28}$

In conclusion, these data show neo-PV stenosis is not an uncommon event after neonatal ASO, even if a uniform surgical procedure is adopted. A small neo-PV anulus before the operation may predict development of neo-PV stenosis after the ASO in neonates.

\section{REFERENCES}

1. Castaneda AR, Trusler GA, Blackstone EH, Kirklin JW, and the Congenital Heart Surgeons Society. The early results of treatment of simple transposition in the current era. J Thorac Cardiovasc Surg 1988;95:14-28.

2. Quaegebeur JM, Rohmer J, Ottemkamp J, et al. The arterial switch operation: an eight-year experience. J Thorac Cardiovasc Surg 1986;92:361-84.

3. Yamaguchi M, Hosokawa Y, Imai Y, et al. Early and midterm results of the arterial switch operation for transposition of the great arteries in Japan. J Thorac Cardiovasc Surg 1990;100:262-9.

4. Idriss FS, IIbawi MN, DeLeon SY, et al. Transposition of the great arteries with intact ventricular septum. J Thorac Cardiovasc Surg 1988;95:255-62.

5. Kirklin JW, Blackstone EH, Tchervenkov CI, Castaneda AR, and the Congenital Heart Surgeons Society. Clinical outcomes after the arterial switch operation for transposition: patients, support, procedural, and institutional risk factors. Circulation 1992;86:1501-15.

6. Trusler GA, Castaneda AR, Rosenthal A, Blackstone EH, Kirklin JW, and the Congenital Heart Surgeons Society. Current results of management in transposition of the great arteries, with special emphasis on patients with associated ventricular septal defect. J Am Coll Cardiol 1987;10:1061-71.

7. Sidi D, Planche C, Kachaner J, et al. Anatomic correction of simple transposition of the great arteries in 50 neonates. Circulation 1987;75:429-35.

8. Martin MM, Snider AR, Bove EL, et al. Two-dimensional and Doppler echocardiographic evaluation after arterial switch repair in infancy for complete transposition of the great arteries. Am J Cardiol 1989;63:332-6.

9. Lupinetti FM, Bove EL, Minich LL, et al. Intermediate-term survival and functional results after arterial repair for transposition of the great arteries. J Thorac Cardiovasc Surg 1992;103:421-7.

10. Zeevi B, Keane JF, Perry SB, Lock JE. Balloon dilation of post operative right ventricular outflow tract obstructions. J Am Coll Cardiol 1990;14:401-8.

11. Pailloe C, Sidi D, Kachaner J, et al. Fate of pulmonary artery after anatomic correction of the simple transposition of the great arteries in new born infants. Circulation 1988;78:870-6.

12. Lecompte Y, Zannini L, Hazan E, et al. Anatomic correction of the transposition of the great arteries: new technique without use of a prosthetic conduit. J Thorac Cardiovasc Surg 1981;82:629-31.

13. Gleason MM, Chin AJ, Andrews BA, et al. Two-dimensional and Doppler echocardiographic assessment of neonatal arterial repair for transposition of the great arteries. J Am Coll Cardiol 1989;13:1320-8.

14. Nakanishi T, Momoi N, Satoh M, et al. Growth of the neopulmonary valve annulus after arterial switch operation in transposition of the great arteries. Circulation 1996; 94(suppl):II27-31.

15. Marino B, Ballerini L, Marcelleti C, et al. Right oblique subxyphoid view for two-dimensional echocardiographic visualization of the right ventricle in congenital heart disease. Am J Cardiol 1988;4:1064-8.

16. Isaaz K, Cloez JL, Danchin N. Marcon F, Worms AM, Pernot C. Assessment of right ventricular outflow tract in children by two-dimensional echocardiography using a new subcostal view: angiographic and morphologic correlative study. Am J Cardiol 1985;56:539-45.

17. Yamaguchi M. Arterial switch operation [Reply to the editor]. J Thorac Cardiovasc Surg 1990;100:314.

18. Takeuchi S, Katogi T. New technique for arterial switch operation in difficult situations. Ann Thorac Surg 1990;50: 1000-1.

19. Wernovsky G, Hougen TJ, Walsh EP, et al. Midterm results after the arterial switch operation for transposition of the great arteries with intact ventricular septum: clinical, homodynamic, echocardiographic, and electrophysiologic data. Circulation 1988;77:1333-44.

20. Serraf A, Bruniaux J, Lacour-Gayet F, et al. Anatomic correction of transposition of the great arteries with ventricular septal defect. J Thorac Cardiovasc Surg 1991;102:140-7.

21. Serraf A, Lacour-Gayet F, Bruniaux J, et al. Anatomic correction of the transposition of the great arteries in neonates. J Am Coll Cardiol 1993;22:193-200.

22. Serraf A, Roux D, Lacour-Gayet F, Touchot A, Bruniaux J, Sousa-Uva M. Reoperation after the arterial switch operation for transposition of the great arteries. J Thorac Cardiovasc Surg 1995;110:892-9.

23. Wernovsky G, Mayer JE, Jonas RA, et al. Factors influencing early and late outcome of arterial switch operation for transposition of the great arteries. J Thorac Cardiovasc Surg 1995;109:289-302.

24. Moss AJ, Adams FH. Transposition of the great arteries. In: Paul MH, Werenovsky G, editors. Heart disease in infants, children, and adolescents: including the fetus and young adult. 5th ed. Baltimore: Williams \& Wilkins; 1995. p. 1154-224.

25. Spiegelenberg SR, Hutter PA, van de Wal HJCM, Hitchcock JF, Meijboom EJ, Harinck E. Late re-interventions following switch operations in transposition of the great arteries: incidence and surgical treatment of postoperative pulmonary stenosis. Eur J Cardiothorac Surg 1995;9:7-11.

26. Yasui H, Yonenaga K, Kado H, et al. Arterial switch operation for transposition of the great arteries: surgical technique to avoid complications. J Cardiovasc Surg 1992;33:511-7.

27. Hourihan M, Colan SD, Wernovsky G, Maheswari U, Mayer JE, Sanders S. Growth of the aortic anastomosis, annulus and root after arterial switch procedure performed in infancy. Circulation 1993;88:615-20.

28. Brooks JW. Aortic resection and anastomosis in pups studied after reaching adulthood. Ann Surg 1950;132:1035-51. 